\title{
Influence of Deposition Parameters and Thermal Annealing on the Structure and Properties of Nitride Coatings $(\mathrm{TiHfZrVNb}) \mathrm{N}$
}

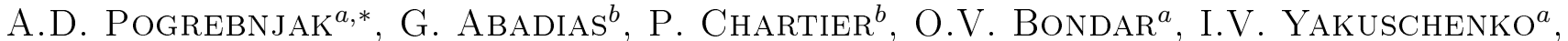

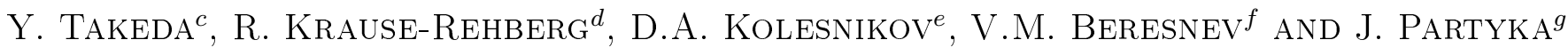

${ }^{a}$ Sumy State University, Rymskogo-Korsakova 2, Sumy, 40007, Ukraine

${ }^{b}$ Institut P', Université de Poitiers CNRS ENSMA, SP2MI, Téléport 2, F86962 Chasseneuil Futuroscope, France

${ }^{c}$ National Institute for Materials Science (NIMS), 3-13 Sakura, Tsukuba, Ibaraki, 305-0003, Japan

${ }^{d}$ Martin-Luther-Universität Halle-Wittenberg, Universitätplatz 10, 06108 Halle, Germany

${ }^{e}$ Belgorod State University, Pobedy 85, 308015, Belgorod, Russia

${ }^{f}$ V.N. Karazin Kharkiv National University, maj. Svobody 4, 61022, Kharkiv, Ukraine

${ }^{g}$ Lublin University of Technology, Nadbystrzycka 38a, 20-618 Lublin, Poland

\begin{abstract}
Results of structure, phase composition, physical and mechanical properties and tribological properties investigations of nitride high-entropy coatings (TiZrHfVNb)N are presented in the paper. Proton microbeam ( $\mu$-PIXE), X-ray diffraction method, including method of X-ray strains measurements, energy dispersive X-ray spectroscopy and scanning electron microscopy analysis, microhardness testing and nanoindentation were used. Thermal annealing $\left(t=600^{\circ} \mathrm{C}\right)$ influence on defect profiles, structure and element distribution in the coatings was investigated. It was found that thermal treatment of coatings leads to changing of defect profiles and to element redistribution. Also we can say that it influences less on grain size changing. Investigated (TiZrHfVNb)N coatings demonstrate high values of hardness and excellent wear resistance.
\end{abstract}

DOI: $10.12693 /$ APhysPolA.125.1296

PACS: 61.46.-w, 62.20.Qp, 62.25.-g

\section{Introduction}

One of the most important tendencies of modern material science is creation of new materials with excellent physical and mechanical properties, high wear resistance and stable structure [1-4]. High entropy alloys (HEAs) and nitrides, based on them, are representatives of such kind of materials [5-9], which have unique spectrum of properties due to which they can be used for different purposes. Therefore, obtaining and investigation of properties and characteristics of (TiZrHfVNb)N coatings is an actual and perspective scientific task.

Explanation of opportunity of creating of nitride system, based on high-entropy alloy TiZrHfVNb is that Hf, $\mathrm{Zr}$ and $\mathrm{Ti}$, as well as $\mathrm{Nb}$ and $\mathrm{V}$, can form continuous series of solid solutions with hcp lattice. At the same time, $\mathrm{V}, \mathrm{Nb}, \mathrm{Zr}$ and $\mathrm{Hf}$ are $\beta$-stabilizers for $\mathrm{Ti}$, i.e. they can reduce temperature of $\mathrm{Ti}$ polymorphic transformation. Thus, using vacuum-arc deposition, nitride (TiZrHfVNb)N with stable structure and high operational characteristics can be obtained.

Usage of nitrides, based on high-entropy alloys, is very interesting and perspective [10,11] not only for creating of protective coatings, but also for creating of diffusion

\footnotetext{
*corresponding author; e-mail: alexp@i.ua
}

barriers. However there is an influence of thermal factor on operational parameters of diffusion barriers. That is why it is very important to investigate thermal stability of such coatings. For this purpose nitride HEAs (TiZrHfVNb)N were subjected to thermal annealing for 30 min under the temperature of $600^{\circ} \mathrm{C}$.

\section{Results and discussion}

Investigated coatings based on high-entropy alloys (TiZrHfVNb)N were obtained by evaporation of cathode arc using "Bulat-6" device. The following deposition parameters were used: negative bias $\left(U_{\mathrm{b}}\right)$ was varied from $-40 \mathrm{~V}$ to $-200 \mathrm{~V}$, arc current reached $85 \mathrm{~A}$, and pressure of working gases $(P)$ was varied from 0.03 to $0.5 \mathrm{~Pa}$. Deposition parameters of investigated coatings and some calculated and measured parameters (lattice parameter and hardness) are shown in Table I.

As a result of structure and phase analysis it was found that fcc lattice is formed in as-deposited coatings. Crystal bcc lattice is formed in non-nitride HEAs TiZrHfVNb. Also, analysis of diffraction spectra shows that increase of voltage bias $U_{\mathrm{b}}$, and decrease of working gas pressure leads to increase of intensity of crystallographic plane (111), i.e. patterning of coatings and growth of structure perfection in direction, which is perpendicular to the plane of the coating's growth.

Figure 1a and $\mathrm{b}$ shows X-ray diffraction (XRD) spectra of coatings of samples No. 504 and No. 508 before and 
TABLE I

Parameters of deposition, lattice parameter, and hardness of nitride high-entropy alloys (TiZrHfVNb)N.

\begin{tabular}{l|c|c|c|c|c}
\hline \hline No. & Material & $U_{\mathrm{b}}[\mathrm{V}]$ & $P[\mathrm{~Pa}]$ & $\begin{array}{c}\text { Lattice } \\
\text { arameter } \\
a[\mathrm{~nm}]\end{array}$ & $\begin{array}{c}\text { Hardness } \\
{[\mathrm{GPa}]}\end{array}$ \\
\hline 504 & (TiZrHfVNb)N & -200 & $7 \times 10^{-1}$ & 0.4420 & - \\
505 & (TiZrHfVNb)N & -110 & $5 \times 10^{-1}$ & 0.4405 & $44.34^{*}$ \\
506 & (TiZrHfVNb)N & -100 & $2 \times 10^{-1}$ & 0.4380 & $24.78^{* *}$ \\
507 & (TiZrHfVNb)N & -50 & $5 \times 10^{-1}$ & 0.4362 & $20.78^{* *}$ \\
508 & (TiZrHfVNb)N & -100 & $1 \times 10^{-1}$ & 0.4380 & - \\
509 & (TiZrHfVNb)N & -100 & $3 \times 10^{-2}$ & 0.4376 & $41.58^{*}$ \\
510 & (TiZrHfVNb)N & -50 & $2 \times 10^{-1}$ & 0.4395 & - \\
512 & (TiZrHfVNb)N & -200 & $8 \times 10^{-2}$ & 0.4435 & $41.18^{*}$ \\
513 & TiZrHfVNb & -40 & $8 \times 10^{-2}$ & 0.3371 & - \\
514 & (TiZrHfVNb)N & -200 & $2 \times 10^{-1}$ & 0.4435 & $27.56^{* *}$ \\
515 & (TiZrHfVNb)N & -200 & $3 \times 10^{-2}$ & 0.4433 & - \\
523 & (TiZrHfVNb)N & -230 & $2.3 \times 10^{-1}$ & 0.4408 & $35.98^{*}$ \\
\hline
\end{tabular}
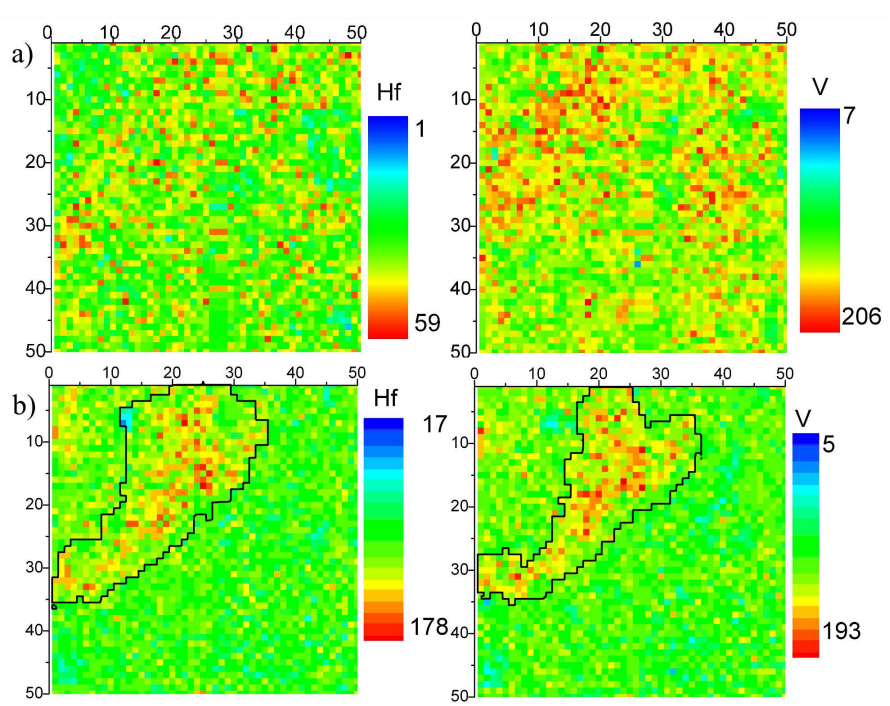

after annealing. From the X-ray strain measurements data it follows that for current series of samples value of lattice parameter in unstressed state is equal to $a=$ $0.442 \mathrm{~nm}$ (for sample No. 504) and $a=0.438 \mathrm{~nm}$ (for sample No. 508).

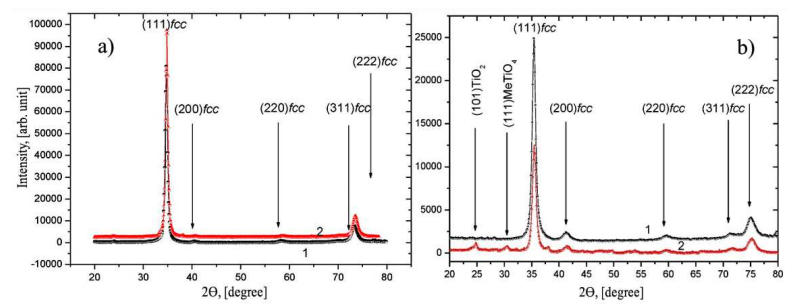

Fig. 2. Element distribution maps for an area of $2.5 \times$ $2.5 \mu \mathrm{m}^{2}$ (the raster is $50 \times 50$, the step size is $0.5 \mu \mathrm{m}$ ) for the sample 504 before (a) and after (b) annealing.

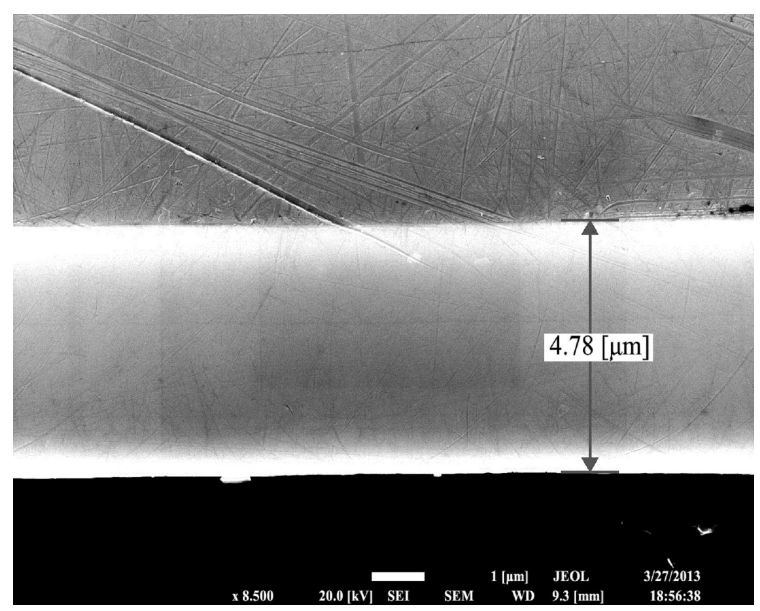

Fig. 1. The XRD spectra for a coating fabricated at (a) $P_{\mathrm{N}}=0.7 \mathrm{~Pa}$ and $U_{\mathrm{b}}=-200 \mathrm{~V}$ (sample 504); (b) $P_{\mathrm{N}}=0.2 \mathrm{~Pa}$ and $U_{\mathrm{b}}=-50 \mathrm{~V}$ (sample 508). (1) before annealing, (2) - after thermal annealing under the temperature of $873 \mathrm{~K}$.

After thermal annealing (under the temperature of $600{ }^{\circ} \mathrm{C}$ for $30 \mathrm{~min}$ ) no significant changes of structure and phase state are observed (peaks intensity remains the same, and type of crystal lattice also remains the same). However, the changes in the stress-strain state are observed - for the first sample it decreases from $-2.76 \%$ to $-2.29 \%$ after annealing, and for the second sample from $-1.9 \%$ to $-0.7 \%$ (more significantly).

Using proton micro-beam ( $\mu$-PIXE) we obtained element distribution maps in the $2.5 \times 2.5 \mu \mathrm{m}^{2}$ area for sample No. 504 before (Fig. 2a) and after (Fig. 2b) annealing. As it follows from Fig. 2, evenly distribution of elements over the depth and on the coating surface is observed.

However, after thermal annealing treatment under the temperature of $600^{\circ} \mathrm{C}$, segregation of impurities at the grain interfaces is observed, and these regions are clearly seen on the maps (Fig. 2b). Thermal annealing leads to segregation of impurities due to diffusion, and on

Fig. 3. SEM image of cross-section of sample No. 515.

the small borders small "glue" phase is formed. Thus, thermal annealing leads to element redistribution in the coating.

Figure 3 shows SEM images of cross-section of sample No. 515. One can see that there is a clear boundary between the coating and the substrate. This boundary has no voids, and it can probably create positive influence on adhesion between substrate and coating. The coating is quite dense, and its thickness $d$ is equal to $4.78 \mu \mathrm{m}$.

The spectra of element composition of cross-section are shown in Fig. 4. Also, concentrations of elements are given in Table II. Presence of $\mathrm{Cr}$ and $\mathrm{Fe}$ on the spectrum ( $16.24 \%$ and $52.6 \%$, respectively) can be explained in a way that these elements are in the material of substrate.

Hardness values for some coatings series are shown in Table I. These systems demonstrate high hardness values 


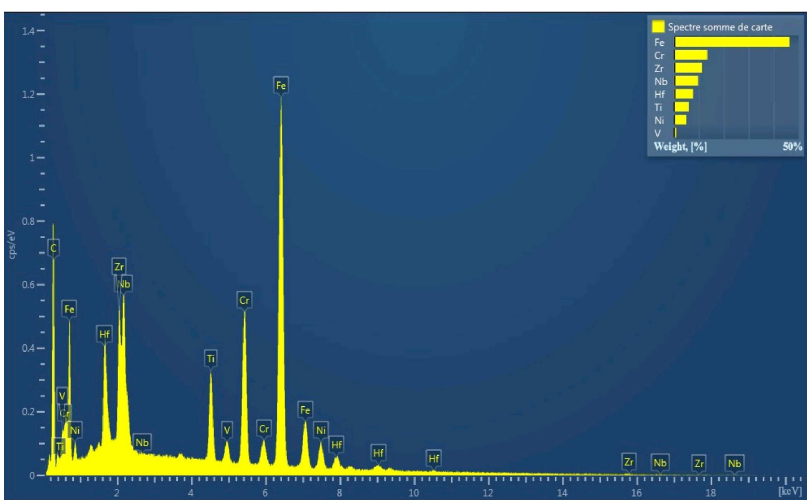

Fig. 4. The spectrum of elemental composition of the coating (TiZrHfVNb)N cross-section.

\section{TABLE II}

The elemental composition of the coating (TiZrHfVNb)N cross-section.

\begin{tabular}{c|c}
\hline \hline Element & $\begin{array}{c}\text { Concentration } \\
\text { [at.\%] }\end{array}$ \\
\hline $\mathrm{Ti}$ & 7.76 \\
$\mathrm{~V}$ & 1.01 \\
$\mathrm{Cr}$ & 16.24 \\
$\mathrm{Fe}$ & 52.6 \\
$\mathrm{Ni}$ & 5.34 \\
$\mathrm{Zr}$ & 7.75 \\
$\mathrm{Nb}$ & 6.58 \\
$\mathrm{Hf}$ & 2.72 \\
total [\%] & 100
\end{tabular}

— from 20.78 GPa to 44.34 GPa. Some difference in these values can be explained by different methods of measurements. Nevertheless, we can claim that nitrides based on high entropy alloys (TiZrHfVNb)N demonstrate excellent mechanical properties.

\section{Conclusions}

Thus, as a result of provided investigations, it was found that coatings based on nitrides of high entropy alloys (TiZrHfVNb)N have fcc crystal lattice, stable structure, and demonstrate high values of mechanical hardness.

It was also established that thermal annealing treatment of investigated coatings leads to changes of the stress-strain state, slight changes of grain sizes, and causes element redistribution over the depth and on the surface of coatings, and also to impurities segregation.

\section{Acknowledgments}

Current work was done in the framework of the budget themes No. 0112 U001382 and No. 0113 U000137 of Ministry of Education and Science of Ukraine.

\section{References}

[1] A.D. Pogrebnjak, A.P. Shpak, N.A. Azarenkov, V.M. Beresnev, Phys. Usp. 52, 29 (2009).

[2] P. Zukowski, T. Koltunowicz, J. Partyka, Yu.A. Fedotova, A.V. Larkin, Vacuum 83, S280 (2009).

[3] A.V. Larkin, A.K. Fedotov, J.A. Fedotova, T.N. Koltunowicz, P. Zukowski, Mater. Sci.Poland 30, 75 (2012).

[4] A.V. Khomenko, Phys. Lett. A 329, 140 (2004).

[5] A.D. Pogrebnjak, A.G. Ponomarev, A.P. Shpak, Yu.A. Kunitskii, Phys. Usp. 55, 270 (2012).

[6] A.D. Pogrebnjak, V.M. Beresnev, A.A. Demianenko, V.S. Baidak, F.F. Komarov, M.V. Kaverin, N.A. Makhmudov, D.A. Kolesnikov, Phys. Solid State 54, 1882 (2012).

[7] A.D. Pogrebnyak, O.V. Sobol, V.M. Beresnev, Tech. Phys. Lett. 35, 925 (2009).

[8] V. Dolique, A.L. Thomann, P. Brault, Y. Tessier, P. Gillon, Mater. Chem. Phys. 117, 142 (2009).

[9] A. Li, X. Zhang, Acta Metall. Sin. 22, 219 (2009).

[10] A.D. Pogrebnyak, V.M. Beresnev, D.A. Kolesnikov, M.V. Kaverin, A.P. Shypylenko, K. Oyoshi, Y. Takeda, R. Krause-Rehberg, A.G. Ponomarev, Tech. Phys. Lett. 39, 280 (2013).

[11] M. Tsai, C. Wang, C. Tsai, W. Shen, J. Yeh, J. Gan, W. Wu, J. Electrochem. Soc. 158, H1161 (2011). 